\title{
The educational needs of nursing staff taking care of patients with rheumatoid arthritis
}

\author{
Tiina Romppanen ${ }^{* 1}$, Anja Rantanen ${ }^{2}$, Liisa Kuokkanen ${ }^{3}$, Kaija Roine-Mentula ${ }^{3}$, Riitta Vuorinen ${ }^{4}$, Tarja Suominen ${ }^{2}$ \\ ${ }^{1}$ North Karelia Central Hospital and Honkalampi Centre, Joensuu, Finland \\ ${ }^{2}$ University of Tampere, Tampere, Finland \\ ${ }^{3}$ Pirkanmaa Hospital District, Tampere, Finland \\ ${ }^{4}$ Helsinki \& Uusimaa Hospital District, Helsinki, Finland
}

Received: February 15, 2015

DOI: $10.5430 /$ jnep.v5n8p44
Accepted: April 7, $2015 \quad$ Online Published: May 22, 2015

URL: http://dx.doi.org/10.5430/jnep.v5n8p44

\begin{abstract}
Objective: This study looks to describe the kind of education needed by nurses taking care of patients with Rheumatoid arthritis. Methods: Survey data concerning nurses' educational needs was collected from 11 hospitals with 33 units in two of the biggest hospital districts in Finland. The data was analyzed using thematic and summative content analysis.

Results: The educational needs of nurses concerned medicinal treatment as an entirety, multiform information about RA, multiform treatment processes of RA, specified questions of care of RA patients, RA as a part of the everyday life of the RA patient and his/her family, the emotional nursing of the RA patient and his/her loved ones, and the strengthening of nurses' abilities to encounter patients. Education needs concerning medical issues comprised $76 \%$ of the responses. Needs connected to special questions of care covered $15 \%$, and needs connected to emotional nursing, the patients' everyday life and to encounters with RA patients and their loved ones comprised $9 \%$.

Conclusions: Nurses wanted to strengthen their information base in all areas, especially those which were medically related. Educational needs concerning other professionals' areas of knowledge (e.g., physiotherapist) might indicate that nurses want to offer all-encompassing care to their patients.
\end{abstract}

Key Words: Rheumatoid arthritis, Registered and practice nurses educational needs, Nursing

\section{INTRODUCTION}

Rheumatoid arthritis (RA) widely affects patients' everyday lives ${ }^{[1-3]}$ and has physical, psychological and social impacts. ${ }^{[4]}$ In Finland, newly diagnosed RA patients have their follow-up controls in hospital, but otherwise care takes place in local health centres. Controls continue to take place in hospital if the patient's disease is active. Otherwise, rheumatology or district nurses with physicians monitor the patient in health centres when the RA is in remission. ${ }^{[5]}$ Very few RA patients undergo primary admission to hospital wards due to RA, but as a secondary diagnosis RA is rather common. The Finnish Medical Society Duodecim $(2009)^{[6]}$ has published national Current Care Guidelines concerning RA but it's focus is mainly on medical information and treatment of the disorder.

Rheum nurses already take on a wide range of clinical activities and it is expected their role will widen to areas traditionally managed by doctors Goh, et al. (2006). ${ }^{[7]}$ In Sweden, the role of the nurse has primarily been connected to the recognition of the patients' physiological, psychological and

\footnotetext{
*Correspondence: Tiina Romppanen; Email: tiina.romppanen@pkssk.fi; Address: North Karelia Central Hospital and Honkalampi Centre, Joensuu,
} Finland. 
sociological need for care, and to the planning of that care. ${ }^{[4]}$ The demands involved in rheum nursing are wide-range. It has been suggested that rheum nurses should master several areas of nursing: e.g., provide help with the activities of daily living, pain management, maintaining tissue viability, patient education, intra articular injections and management of intravenous drug therapy. ${ }^{[8]}$ Furthermore, rheum nurses require a knowledge and understanding of rheumatic diseases, drug therapies, good communication skills, an understanding of team roles, working effectively as part of a multidisciplinary team, the assessment of patients by physical examination, teaching and education, research, organizational skills, the interpretation of investigations, drug monitoring, counselling of patients, arranging basic investigations, ${ }^{[7]}$ and also patient education. ${ }^{[9]}$ The Royal College of Nursing (2001) has in turn determined that nurses should concentrate on three areas of care concerning RA patients. These areas are disease knowledge and management, self-care abilities, and social and environmental factors. ${ }^{[8]}$ In multi-professional teams, nurses' duties are assessment, co-ordination and communication, technical and physical care, therapy interaction and carry on, emotional support and involving the family. ${ }^{[10]}$

There are only a limited number of studies available concerning nurses' educational needs in the care of patients with RA. Fletcher et al. ${ }^{[11]}$ found that practice nurses do not feel confident or competent in their knowledge and ability to manage musculoskeletal conditions, however an overall willingness among nurse practitioners to develop their role has been identified. ${ }^{[7]}$ Lillie et al. ${ }^{[12]}$ found that nurses felt a lack of knowledge in giving advice on exercise and pain medication. This article examines the educational needs of registered and practice nurses taking care of patients with RA, both in basic and special health care facilities, and hospital wards and out-patient units.

\section{METHODS}

\subsection{Data}

Data concerning nurses' educational needs was collected by questionnaire from nursing staff taking care of patients with RA. Data was collected in 2011 from 11 hospitals with 33 units in two of the biggest hospital districts in Finland. Fourteen of the units were outpatient or daycare units and 19 were inpatient units. Patients treated in the units were mainly adults but some of the units also treated children. Questionnaires were given out to the ward or head nurses of the units involved and they delivered the questionnaires to their nursing personnel. In the whole study 602 questionnaires were given out and 197 returned. One questionnaire was rejected.

The questionnaire used consisted of three sections: 1) Back- ground factors; 2) Work Empowerment Questionnaire; ${ }^{[13]}$ and 3) Nurse Empowerment. ${ }^{[14]}$ Both instruments had been previously used in Finnish context. The data was analysed by using statistical methods and those results were reported in a Finnish nursing science journal. ${ }^{[15]}$

Nurses' educational needs were examined by an open-ended question concerning whether the nurse thought she/he needed more education concerning the care of RA patients or taking notice of their loved ones, and what kind of education it would be. Some of the responses consisted of single words and some of multiple sentences. Altogether, 136 responses were received. Four were rejected as they did not answer the research question, so ending up with a total of 132 responses.

\subsection{Analysis}

Thematic analysis was chosen as preferred method due to its versatility and ability to produce concise data. ${ }^{[16]}$ Thematic analysis involves the searching across a data set to find repeated patterns of meaning, ${ }^{[17]}$ and it was felt that the approach gave more freedom to the researchers to maintain the spirit of the original data. The original data was read through several times and it was during this phase that similarities within the data were found. The thematic analysis process starts when the analyst begins to notice (and look for) patterns of meaning and issues of potential interest in the data. ${ }^{[17]}$ Thematic analysis is a method for identifying, analyzing and reporting patterns (themes) within data. ${ }^{[17]}$ Analysis proceeds through six phases: 1) familiarization with the data, 2) coding, 3) searching for themes, 4) reviewing themes, 5) defining and naming themes and 6) writing up and producing a report. ${ }^{[17,18]}$

The analysis proceeded as described and the research group monitored the process at regular stages. First writer was the primary analyst. Analysis was performed in Finnish and the results translated into English. An analysis table was compiled that included all of the relevant original expressions and codes (11 pages in total). During the analysis process themes were examined, renamed and reorganized. Translated examples of authentic expressions are introduced in the results (see Table 1).

Following theme analysis, the data was also analyzed using summative content analysis. Summative content analysis is a form of content analysis where counting and comparisons (usually of keywords or content) is used to explore usage. ${ }^{[16]}$ Summative content analysis was decided to be performed because some of the themes occurred very strongly within the original data. The counting phase was implemented using a table where all of the relevant original expressions were combined (see Table 2). 


\subsection{Ethical approval}

Permissions to carry out the study were obtained from the organizations concerned. Respondents were given written information assuring them about issues of anonymity and confidentiality.

Table 1. Main theme and subthemes

\begin{tabular}{|c|c|c|}
\hline Main themes & Subthemes & Examples of original complete replies \\
\hline \multirow{5}{*}{$\begin{array}{l}\text { Medication } \\
\text { treatment of RA as } \\
\text { entirety }\end{array}$} & Medication as a part of treatment of RA & Intermittent checking-up of knowledge, concerning medications + treatment. \\
\hline & Changing medication & $\begin{array}{l}\text { Medication has developed -> constant education. Progressing medication!!! In } \\
10 \text { years massive development. Information of rheum surgical patients different } \\
\text { operations -> developing biomaterials that are used i.e., in arthroplasties. A } \\
\text { nurse can better inform the patient because (they) sometimes ask a lot. }\end{array}$ \\
\hline & Biological medication & $\begin{array}{l}\text { Overall about different RA diseases. At the moment I have to find all } \\
\text { information myself. Also biological drugs interest. }\end{array}$ \\
\hline & The follow-up (protocol) of medication & Injection teaching, nutrition, “non-medication”, follow-up blood tests. \\
\hline & $\begin{array}{l}\text { Side-effects and interactions of } \\
\text { medications }\end{array}$ & $\begin{array}{l}\text { Current treatment forms, their effectivity and side-effects and long-time } \\
\text { prognosis. }\end{array}$ \\
\hline \multirow{3}{*}{$\begin{array}{l}\text { Multiform } \\
\text { information about } \\
\text { RA }\end{array}$} & $\begin{array}{l}\text { Strengthening of already existing } \\
\text { information }\end{array}$ & $\begin{array}{l}\text { Constant update of information about new treatments and clinical pathways } \\
\text { because I treat other patients than rheum patients and do administration also. }\end{array}$ \\
\hline & Medical information base & $\begin{array}{l}\text { Basic education. } \\
\text { Basic information of RA diseases and medication. } \\
\text { Information of medication and different RA types. }\end{array}$ \\
\hline & Information of a child as a RA patient & Medication treatment, of RA in children. \\
\hline \multirow{6}{*}{$\begin{array}{l}\text { Multiform } \\
\text { treatment process } \\
\text { of RA }\end{array}$} & Overall clinical pathways and guidelines & $\begin{array}{l}\text { Additional information of clinical pathways. Käypä hoito (name of the national } \\
\text { guideline) -update. }\end{array}$ \\
\hline & $\begin{array}{l}\text { The first phase of a RA patient's } \\
\text { treatment process }\end{array}$ & $\begin{array}{l}\text { Of pain medication and of it's impact to other medication. Of rheum medication } \\
\text { and their impact to other medication. Changes in blood count. Best helping } \\
\text { means in the acute stage. }\end{array}$ \\
\hline & $\begin{array}{l}\text { The progress of the illness on patients' } \\
\text { perspective }\end{array}$ & Recognition of symptoms and counseling. \\
\hline & Medical treatment of RA & $\begin{array}{l}\text { At the moment there are few RA patients in our ward - if patients come then I } \\
\text { would like to have the latest/ updated information and treatment guidelines. }\end{array}$ \\
\hline & Operative treatment & $\begin{array}{l}\text { Rheum diseases and their treatment (medication treatment, operative care, } \\
\text { physiatry-, psychiatric...). }\end{array}$ \\
\hline & $\begin{array}{l}\text { The effectivity and side-effects of } \\
\text { treatment forms }\end{array}$ & $\begin{array}{l}\text { Modern treatment forms, their effectivity and side-effects and long-term } \\
\text { prognosis. }\end{array}$ \\
\hline \multirow{5}{*}{$\begin{array}{l}\text { Specified questions } \\
\text { about care }\end{array}$} & Rehabilitating care & The medication of RA patients, rehabilitation, quality of life, RA as a disease. \\
\hline & Assistive devices & Information of the disease and medication. Of assistive devices/ benefits. \\
\hline & Pain in the treatment of RA & Treatment of pain, assistive devices to patients. \\
\hline & Nutrition in the treatment of RA & $\begin{array}{l}\text { Of medication, rehabilitating care, possible impacts of nutrition to RA. Of } \\
\text { exercise forms, biological drugs. }\end{array}$ \\
\hline & Social security & $\begin{array}{l}\text { Newest medication treatments/medical treatment forms, social security, latest } \\
\text { information of physiotherapy, newest information. }\end{array}$ \\
\hline \multirow{3}{*}{$\begin{array}{l}\text { RA as a part of } \\
\text { everyday life of the } \\
\text { RA patient and } \\
\text { his/her family }\end{array}$} & $\begin{array}{l}\text { The experience of illness of the RA } \\
\text { patient and his/her family }\end{array}$ & $\begin{array}{l}\text { Medication (new drugs) and concerning rehabilitation. Also about the impact of } \\
\text { rheum to general state of health. }\end{array}$ \\
\hline & Living with RA & General diseases/medication treatment- impact of RA to life. \\
\hline & $\begin{array}{l}\text { The survival of everyday life of the RA } \\
\text { patient and his/her family }\end{array}$ & $\begin{array}{l}\text { In internal medicine ward such sick patients with comorbid conditions that } \\
\text { information would be needed in many of the specialties. Also general } \\
\text { information would be good: medication, surviving of the everyday chores etc. }\end{array}$ \\
\hline \multirow{2}{*}{$\begin{array}{l}\text { Emotional nursing } \\
\text { of the RA patient } \\
\text { and his/her loved } \\
\text { ones }\end{array}$} & Giving support to family and loves ones & Newest medication. The overall support of the RA patients and loved-ones. \\
\hline & Emotional support & $\begin{array}{l}\text { How to treat/care rheum patients "rightfully" and what kind of support the loved } \\
\text { ones usually need. }\end{array}$ \\
\hline \multirow{2}{*}{$\begin{array}{l}\text { Strengthening } \\
\text { nurses' abilities to } \\
\text { encounter patients }\end{array}$} & Nurses' abilities & $\begin{array}{l}\text { You can never have too much training about encountering challenging } \\
\text { situations. }\end{array}$ \\
\hline & Counseling of the RA patient & $\begin{array}{l}\text { Matters (i.e., everyday functioning/moving) concerning counseling of those in } \\
\text { poor shape. }\end{array}$ \\
\hline
\end{tabular}


Table 2. Summative content analysis of the data

\begin{tabular}{ll}
\hline Main theme & $\mathbf{N}, \mathbf{\%}$ \\
\hline Medication treatment as an entirety & $\mathrm{N}=84,30 \%$ \\
Multiform information about RA & $\mathrm{N}=82,29 \%$ \\
Multiform treatment process of RA & $\mathrm{N}=49,17 \%$ \\
Special questions about care & $\mathrm{N}=43,15 \%$ \\
RA as a part of everyday life of the RA patient and his/her family & $\mathrm{N}=13,5 \%$ \\
Emotional nursing of the RA patient and his/her loved ones & $\mathrm{N}=7,2 \%$ \\
Strengthening of nurses' ability to encounter patients & $\mathrm{N}=7,2 \%$ \\
\hline
\end{tabular}

\section{RESULTS}

\subsection{Participants}

Of the relevant replies $(n=132)$, almost all of the respondents were women $(96 \%)$. On average, the respondents were 43 years old (SD 10.8), they had an average work experience 16 years (range 1-40) after initial nursing education (RN or practice nurse education), and had been in their current job for 10 years (range 1-36). 87\% were registered nurses and $9 \%$ were practice nurses. $4 \%$ had some other degree in health care (e.g., MNSc). 68\% of the respondents worked in inpatient wards and $30 \%$ in outpatient clinics. $2 \%$ worked in both unit types. Respondents had an average experience of caring for RA patients of 10 years (range 0-35) and most had a permanent position (89\%). Of the full original data $(n=196), 85 \%$ of the respondents wanted more education, although slightly over half of them considered their competence to take care of patients with RA to be either good or rather good.

\subsection{Educational needs}

Seven themes were identified. The educational needs of nurses concerned medicinal treatment as an entirety, multiform information about RA, the multiform treatment process of RA, specified questions of care of RA patients, RA as a part of the everyday life of the RA patient and his/her family, the emotional nursing of the RA patient and his/her loves ones, and the strengthening of nurses' abilities to encounter patients (see Table 1). Translated examples of typical original expressions are listed after each theme in cursive font.

Medication treatment as an entirety consisted of five areas: medication as a part of the treatment of RA, changing medication, biological medication, the follow-up of medication regimens and the interactions and side effects of medications. Examples of original expressions used were: of medication, issues related to medication, fact information about different rheum medication; new medications: what special things should I know about them; biological medications; developing pharmacotherapy; synergism of pain medication to other medications; blood tests related to medication.

Multiform information about RA consisted of three areas

Published by Sciedu Press which concerned the strengthening of existing information, medical information, and information on caring for pediatric RA patients. Examples of original expressions used were: repetition, latest information, intermittent knowledge check-up, constant knowledge update of new treatments and treatment processes; basic facts, basic information on RA, different rheum illnesses and special features; RA illness in children.

Multiform treatment processes of RA consisted of six areas: overall treatment care pathways and recommendations, the first phase of an RA patient's treatment process, the progress of the illness from the patient's perspective, medical treatment of RA, operative treatment; and the efficacy and side effects of different treatment forms. Examples of original expressions used were: current care guidelines update; prevention; symptoms; information about the progress of $R A$; different forms of treatment; special features in RA patient treatment; non-medicine treatment; operative treatment; developing biomaterials; side effects of current treatments .

Specified questions about the care of RA covered five areas: rehabilitating care, assistive devices, pain in the treatment of RA, nutrition in the treatment of RA, and social security. Examples of original expressions used were: about rehabilitation; assistive devices for the patient, different forms of exercise; pain management; portion of nutrition; social benefits and compensations.

RA as a part of the everyday life of the RA patient and his/her family consisted of three areas: the experience of illness of the RA patient and his/her family, living with RA, and the survival of everyday life for the RA patient and his/her family. Examples of original expressions used were: the adjustment of the RA patient; living with the illness, quality of life, the impact of RA on life; means of family survival in everyday life.

Emotional nursing of the RA patient and his/her loved ones consisted of two areas: offering support to the loved ones and family, and emotional support. Examples of original expressions used were: what kind of support loved ones usually need; offering support to the parents; psychology. 
Strengthening nurses' abilities to encounter patients consisted of two areas: nurses' abilities, and the counselling of the RA patient. Examples of original expressions used were: care from the nurse's perspective; the skill to give salient/necessary support; you can never get too much education about encountering challenging situations; counselling the unfit.

When counting nurses' responses based on the different themes identified, it was found that nurses' education needs concerning medical issues comprised $76 \%$ of the responses. Needs connected to special questions of care covered $15 \%$, and needs connected to emotional nursing, the patients' everyday life and to encounters with RA patients and their loved ones comprised 9\% (see Table 2). The original expressions used in education areas with more identified needs were quite homogeneous, however smaller educational areas with less identified needs were more heterogeneous in their expression.

\section{Discussion}

Many of the replies raised more than one area of educational need. This made it more difficult to execute a summative content analysis, but also underlined the fact that nursing consists of multiple areas of knowledge and expertise. The manner or style of writing, and the use of certain expressions and describing words, verbs etc. that some of the nurses used hinted that they might feel quite a lot of insecurity while working, due to the lack of basic information. It seems that nurses want a more stable and solid information base to support their everyday work and patient education. An impression that was perceived from the answers was that nurses wanted to strengthen their information base in all areas, but medical information was especially prominent.

Nurses wanted concrete, medicine-based information about RA. Most of the answers concerned a general need for medical information (treatment, medication and basic information), and there was a lesser requirement for education in other areas (e.g., counselling and giving support). Goh et al. $(2006)^{[7]}$ found that the three main areas of skills and knowledge identified by practice nurses were a knowledge and understanding of rheumatic diseases, good communication, and drug therapy. Some nurses appear to carry out their work, insecure on the underlying information needs that it entails, and several answers focused on the need to strengthen the information base. Most of the nurses (73\%) worked in wards with patients from various medical specialties and so the need to have a wide information base accentuates.

Medication was a salient theme and derived the most codes from the analysis. It would appear that education about pharmacology might not be offered to nurses as much as they'd like, or it hasn't been customary to educate nurses as effectively as doctors about changes or new alignments concerning RA medication. A desire by nurses to further educate themselves seems logical when much of the patient' drug therapy and monitoring is directed towards nurses Ryan, et al. (2006), ${ }^{[19]}$ who in Finland work alongside doctors. In regard to medication, this entails specific knowledge of issues such as side-effects, duration of action, utilities and interactions. Nurses' working roles that require pharmacological knowledge have been identified as drug administration, patient assessment, nurse prescribing and patient medication education, and the need to have an expanded knowledge has been recognized due to most nurses' limited understanding of pharmacology. ${ }^{[20]}$ Medication is a very important part of the treatment of RA due to its incurable nature. ${ }^{[21]}$ Pharmacological treatments have changed significantly ${ }^{[4]}$ and some nurses feel that their lack of pharmacology knowledge causes them anxiety, and as a result they lack confidence in providing patient medication education. ${ }^{[20]}$

Nurses also brought up views of the impact of RA on everyday life. Nurses' own attitudes towards RA varied and this was shown in the expressions they used. Some used verbs like surviving with RA, some used coping or living. The need to have more information about the different knowledge of other specialist areas also showed up. Nurses wanted information about physiotherapy, pain management, nutritional therapy, and social benefits and compensations. Nurses seemed to want to prepare themselves for everything a patient might ask them, although other professionals (i.e., physiotherapists) would have more specialized knowledge on some specific issues. The treatment of RA is usually complex and teams taking care of the patient may consist of physiotherapists, occupational therapists, social workers, foot therapists and nutrition therapists, alongside nurses and doctors Arvidsson, et al. , Hale \& Hill. ${ }^{[4,8]}$ In a study by Goh et al. $(2006)^{[7]}$, research nurses reported working in a multidisciplinary team as one area of nursing work, but a study by Fletcher, et al. ${ }^{[11]}$ found that most practice nurses worked in a team consisting of other nurses. In our study, working as a part of a multi-professional group, didn't arise. The need to better understand other professionals' knowledge areas might indicate that most of the nurses involved in the care of RA patients may not have the possibility consult other professionals, or don't have a habit of doing so. As such, they may not work or feel as if they are working as a team.

On the other hand, nurses may want to offer allencompassing care to the patients as a holistic approach to their nursing care. It has been stated that patients reviewed by clinical nurse specialists adjusted better to the impact of 
RA, ${ }^{[19]}$ and so a holistic approach might be effective. In a study by Tuominen et al. (2010), ${ }^{[1]} 87 \%$ of respondents dealt with one or more functional disabilities caused by RA which affected everyday life. Disabilities or perceived disabilities mentioned were e.g., walking, washing windows, opening jars, carrying, or putting on shoes. In a study by Drăgoi et al. (2013), ${ }^{[2]}$ patient's wanted information about ways to ease their everyday life with RA. Questions of this type are most likely to be asked from nurses, especially in basic health care units. Patients have reported satisfaction with the possibility to discuss the management of RA symptoms on everyday life $^{[4]}$ and expressed a sense of empowerment after visits in a nurse-led clinic. ${ }^{[22]}$ The patient's primary nurse has found to be an important person in giving support and education. ${ }^{[22,23]}$

Patient education and offering support were mentioned in substantially smaller amounts than the medicine-based information, but they are tightly connected. A strong information base makes it easier for the nurses to counsel patients, and it has been expressed that nurses should offer more targeted patient education. ${ }^{[2]}$ Families also hope to be involved in counselling and have voiced the opinion that shared participation would improve the execution of self-care at home. ${ }^{[23]}$ Good knowledge of physical exercise and joint protection techniques for RA patients has been correlated with stronger function and self-efficacy of other symptoms. It is felt that one-to-one patient education methods could positively influence patient health behaviors such as self-care, ${ }^{[24]}$ but Tuominen et al. ${ }^{[1]}$ state that many health care professionals haven't experienced the disabilities RA patients face at home and therefore may emphasize functions that are not so immediately relevant to the patient.

Patients' needs vary greatly due to the fluctuating nature of RA. RA patients also delay seeking help in order to maintain a feeling of self-management over RA while using microand crisis management techniques. ${ }^{[3]}$ In studies, it has been found that nurses hope for continuous and regular education concerning patient education, in order to develop themselves as professionals. ${ }^{[9]}$ Practice nurses have also expressed their interest in more training in the provision of counselling. ${ }^{[7]}$

In our study, we also looked at how the respondents answered in regard to their placement in inpatient wards and outpatient clinics. It seems nurses that work in outpatient clinics need advanced information more than nurses working in inpatient wards. This finding seems logical as outpatient clinics are usually more medically focused, while wards have patients stemming from a range of different specialties. However, a large number of outpatient clinic nurses still wanted information on a basic level. Nurses from inpatient wards wanted more education about the treatment of RA, physiotherapy, moving or exercise, assistive devices, and the impact of RA on everyday life. Nurses from outpatient clinics wanted more education about patient education and the general treatment of RA. They also wanted information regarding pediatric patients and the care of RA in children, providing education and support to pediatric patients and their families, and surviving with RA in everyday life.

As multi-professional education is offered to patients, ${ }^{[5]}$ nurses also seemed to want education that was similarly derived. RA has a considerable impact upon the patients' quality of life, ${ }^{[4]}$ and thus the needs of patients also require ever-widening areas of knowledge. Within the professions, education is expected to be continual, and in our study the need for continual and update education was a recurrent theme.

\section{Limitations}

The data was rich in form and ranged from single word responses to multiple sentences. Nurses answered the openended question concerning their educational needs with enthusiasm, and the response rate was $69 \%(n=136 / 196)$. Data was also diverse which indicates that most of the groups educational need areas were likely to have been identified. Also, previous literature (e.g., Hale \& Hill 2006) ${ }^{[8]}$ about the areas of competence and roles supports our findings concerning the main areas of educational needs in this context.

The data was collected three years ago. Although these educational needs may have changed since this period, it is possible that in some units educational needs may continue to exist as they are represented here. The summative content analysis was difficult to perform and it's reliability can therefore be doubted. The exact amount of simplifications would probably differ to a slight degree depending on the person who counts them, due to the nature of the expressions presented. On the other hand, the numbers serve to show the relative strength between different themes and may therefore help managers and supervisors to prioritize educational resources. The thematic analysis was performed by one researcher, but the other research group members commented on the resultant data and confirmed the analytic process at regular intervals. In general however, several of the themes identified in this study could also be found in the model of rheum nursing produced by the Royal College of Nursing, ${ }^{[8]}$ so the results appear consistent with other external sources.

\section{Conclusion}

The main educational needs of nurses' related to medicalbased information (RA as an illness, it's treatment and medication), and also to the provision of support to the patient and their family. Nurses also wanted information about the 
means used to cope with RA everyday life and RA-related knowledge of other professional areas.

Identifying the differences in educational needs between inpatient wards and outpatient clinics would help supervisors to plan their staff's education programs. Further research should investigate the optimal form and frequency of educational measures and whether the improved education shows improved outcomes such as a change in patient safety, clinical efficacy, or patient and staff satisfaction.

\section{ACKNOWLEDGEMENTS}

Help with the translation was provided by the The Written Word.eu company. Funding was allocated for this research by the Department of Science Centre of the Hospital District of Pirkanmaa (Grant \# 9R048).

\section{CONFlicts OF InTEREST Disclosure}

The author declares that there is no conflict of interest statement.

\section{REFERENCES}

[1] Tuominen R, Tuominen S, Suominen C, et al. Perceived functional disabilities among rheumatoid arthritis patients. Rheumatology International. 2010; 30: 643-649. PMid:19593569 http: //dx.doi.org/10.1007/s00296-009-1043-z

[2] Drăgoi R, Ndosi M, Sadlonova M, et al. Patient education, disease activity and physical function: can we be more targeted? A cross sectional study among people with rheumatoid arthritis, psoriatic arthritis and hand osteoarthritis. Arthritis Research \& Therapy. 2013; 15: R156. PMid:24286444 http://dx.doi .org/10.1186/ar4339

[3] Flurey C, Morris M, Richards P, et al. It's like a juggling act: rheumatoid arthritis patient perspectives on daily life and flare while on current treatment regimes. Rheumatology. 2014; 53: 696-703. http://dx.doi.org/10.1093/rheumatology/ket416

[4] Arvidsson B, Jacobsson L, Petersson IF. Rheumatology care in Sweden - the role of the nurse. Guest editorial, Musculoskeletal Care 2003; 1: 81-83. PMid:20217668 http://dx.doi.org/10.1002 /msc. 43

[5] Mäkeläinen P, Vehviläinen-Julkunen K, Pietilä A-M. Rheumatoid arthritis patients' knowledge of the disease and its treatment: A descriptive study. Musculoskeletal Care. 2009; 7: 31-44. PMid:18697184 http://dx.doi.org/10.1002/msc.138

[6] The Finnish Medical Society Duodecim. National Current Care Guidelines, Rheumatoid arthritis. 2009.

[7] Goh L, Samanta J, Samanta A. Rheumatology nurse practioners' perceptions of their role. Musculoskeletal Care. 2006; 4: 88-100. PMid:17042020 http://dx.doi.org/10.1002/msc. 81

[8] Hale C, Hill J. Locating the evidence base for musculoskeletal nursing: an overview of the rheumatology nursing literature. International Journal of Nursing Studies. 2006; 43: 507-518. PMid:16157337 http://dx.doi.org/10.1016/j.ijnurstu.2005.06.006

[9] Kyngäs H, Kukkurainen ML, Mäkeläinen P. Patients education from the perspective of health care providers. 2005.

[10] Long AF, Kneafsey R, Ryan J, et al. The role of the nurse within the multi-professional rehabilitation team. Journal of Advanced Nursing 2002; 37: 70-78. http://dx.doi.org/10.1046/j.1365-2648. 2002.02059.x

[11] Fletcher M, Oliver S, Cook A, et al. An investigation into practice nurses' need for further education in musculoskeletal care. Practice Nursing. 2013; 23: 40-46. http://dx.doi.org/10.12968/pnur .2012 .23 .1 .40

[12] Lillie K, Ryan S, Adams J. The Educational Needs of Nurses and Allied Healthcare Professionals Caring for People with Arthritis: Results from a Cross-Sectional Survey. Musculoskeletal Care. 2013; 11
(2): 93-98. PMid:23065861 http://dx.doi.org/10.1002/msc .1035

[13] Irvine D, Leatt P, Evans M, et al. Measurement of staff empowerment within health service organizations. Journal of Nursing Measurement 1999; 7 (1): 79-95. PMid:10394776

[14] Kuokkanen L. A model of individual and environmental factors. Annales Universitatis Turkuensis D. Painosalama Oy, Turku; 2003.

[15] Romppanen T, Roine-Mentula K, Rantanen A, et al. Empowerment and the promoting and impeding factors of empowerment of nursing staff taking care of patients with rheumatism. Abstract in English. Hoitotiede. 2013; 25(4): 266-78.

[16] Hsieh HF, Shannon SE. Three Approaches to Qualitative Content Analysis. Qualitative Health Research. 2005; 15: $1277-$ 1288. PMid:16204405 http://dx.doi.org/10.1177/1049732 305276687

[17] Braun V, Clarke V. Using thematic analysis in psychology. Qualitative Research in Psychology. 2006; 3: 77-101. http://dx.doi.o rg/10.1191/1478088706qp063oa

[18] Clarke V, Braun V. Teaching thematic analyses: overcoming challenges and developing strategies for effective learning. The Psychologist. 2013; 26: 120-123.

[19] Ryan S, Hassels AB, Lewis M, et al. Impact of a rheumatology expert nurse on the wellbeing of patients attending a drug monitoring clinic. Journal of Advanced Nursing. 2006; 53: 277-286. PMid:16441532 http://dx.doi.org/10.1111/j.1365-2648.2006.03725.x

[20] King RL. Nurses' perceptions of their pharmacology educational needs. Journal of Advanced Nursing. 2004; 45: 392-400. http: //dx.doi.org/10.1046/j.1365-2648.2003.02922.x

[21] Dubey S, Gaffney K. Management of early rheumatoid arthritis. Clinical Medicine. 2005; 5: 211-214. PMid:16011209 http://dx.doi.org/10.7861/clinmedicine.5-3-211

[22] Arvidsson SB, Petersson A, Nilsson I, et al. A nurse-led rheumatology clinic's impact on empowering patients with rheumatoid arthritis: A qualitative study. Nursing and Health Sciences. 2006; 8: 133 139. PMid:16911172 http://dx.doi.org/10.1111/j.1442-2 $018.2006 .00269 . \mathrm{x}$

[23] Vihijärvi S, Koivula M, Åstedt-Kurki P. The families' experiences and expectations of patient education related to rheumatoid arthritis. Abstract in English. Tutkiva Hoitotyö. 2008; 6: 16-22.

[24] Mäkeläinen P, Vehviläinen-Julkunen K, Pietilä AM. Change in knowledge and self-efficacy of patients with rheumatoid arthritis: A sixmonth follow-up study. International Journal of Nursing Practice. 2009; 15: 368-375. http://dx.doi.org/10.1111/j.1440-172 X. 2009.01792.x 